\title{
Aspirin overutilization for the primary prevention of cardiovascular disease
}

This article was published in the following Dove Press journal:

Clinical Epidemiology

I December 2014

Number of times this article has been viewed

\author{
Jeffrey J VanWormer' \\ Aaron W Miller ${ }^{2}$ \\ Shereif H Rezkalla ${ }^{3}$ \\ 'Center for Clinical Epidemiology \\ and Population Health, ${ }^{2}$ Biomedical \\ Informatics Research Center, \\ Marshfield Clinic Research \\ Foundation, Marshfield, WI, USA; \\ ${ }^{3}$ Department of Cardiology, Marshfield \\ Clinic, Marshfield, WI, USA
}

Background: Aspirin is commonly used for the primary prevention of cardiovascular disease (CVD) in the US. Previous research has observed significant levels of inappropriate aspirin use for primary CVD prevention in some European populations, but the degree to which aspirin is overutilized in the US remains unknown. This study examined the association between regular aspirin use and demographic/clinical factors in a population-based sample of adults without a clinical indication for aspirin for primary prevention.

Methods: A cross-sectional analysis was performed using 2010-2012 data from individuals aged 30-79 years in the Marshfield Epidemiologic Study Area (WI, USA). Regular aspirin users included those who took aspirin at least every other day.

Results: There were 16,922 individuals who were not clinically indicated for aspirin therapy for primary CVD prevention. Of these, 19\% were regular aspirin users. In the final adjusted model, participants who were older, male, lived in northern Wisconsin, had more frequent medical visits, and had greater body mass index had significantly higher odds of regular aspirin use $(P<0.001$ for all). Race/ethnicity, health insurance, smoking, blood pressure, and lipid levels had negligible influence on aspirin use. A sensitivity analysis found a significant interaction between age and number of medical visits, indicating progressively more aspirin use in older age groups who visited their provider frequently.

Conclusion: There was evidence of aspirin overutilization in this US population without CVD. Older age and more frequent provider visits were the strongest predictors of inappropriate aspirin use. Obesity was the only significant clinical factor, suggesting misalignment between perceived aspirin benefits and cardiovascular risks in this subgroup of patients. Prospective studies that examine cardiac and bleeding events associated with regular aspirin use among obese samples (without CVD) are needed to refine clinical guidelines in this area.

Keywords: aspirin, primary prevention, cardiovascular disease, adults, United States

\section{Introduction}

Along with lipid and blood pressure control agents, aspirin is a relatively common medication used for the primary prevention of cardiovascular disease (CVD) in the US. ${ }^{1-3}$ Previous studies have concluded that aspirin is cost-effective ${ }^{4}$ and lowers CVD relative risk by $14 \%$ over 7 years. ${ }^{5}$ Aspirin use has steadily increased in the US, ${ }^{6,7}$ with about two of every five adults over age 40 now taking it regularly. ${ }^{8}$ In contrast, aspirin for primary CVD prevention is not as widely embraced in Europe, ${ }^{9,10}$ where rates of prophylactic aspirin use are much lower. ${ }^{11,12}$ Discrepancies in this aspect of medical care area are largely driven by differing evidence bases that underwrite clinical guidelines in different countries (eg, relative weighting of clinical trials versus community studies), ${ }^{13}$ but the US Preventive Services Task Force (USPSTF) currently recommends
Correspondence: Jeffrey J VanWormer

Center for Clinical Epidemiology and Population Health, Marshfield Clinic Research Foundation, 1000 North Oak Avenue, Marshfield, WI 54449, USA

$\mathrm{Tel}+\mathrm{I} 7152216484$

Fax +I 7I5 3893880

Email vanwormer.jeffrey@mcrf.mfldclin.edu 
aspirin for a select group of adults without CVD in whom their risk of incident myocardial infarction or stroke is high and the prospects of cardioprotection are believed to outweigh those of gastrointestinal or intracranial hemorrhage. ${ }^{14}$ These USPSTF guidelines are not wholly uncontested though. Denying a pharmaceutical industry request to openly market aspirin for primary CVD prevention, the US Food and Drug Administration recently advised consumers against taking aspirin for primary CVD prevention. ${ }^{15}$

Studies from both Switzerland and Italy have previously documented population-level overutilization of aspirin for primary CVD prevention, ${ }^{12,16}$ suggesting that more aspirin consumption may disproportionally affect those less likely to benefit and/or more likely to suffer harm from it. There is also a general concern that national or otherwise large healthcare systems tend to be particularly sluggish at reducing unnecessary care. ${ }^{17}$ Very little is known about patterns of inappropriate aspirin use in the US, with just one prior analysis of adults without CVD finding that about two-thirds were not clinically indicated for aspirin per current USPSTF guidelines, yet 18\% reported using aspirin regularly anyway. ${ }^{18}$

Previous aspirin pharmacosurveillance research has mainly highlighted underutilization patterns in populations at high CVD risk. In the few studies that have examined aspirin overuse in primary CVD prevention populations, ${ }^{12,16,18}$ the focus has been limited to general trends or demographic correlates. No studies to date have looked at the influence of clinical factors on inappropriate aspirin use in the US. This is an important research gap to address given the increased scrutiny and uncertainty regarding the use of aspirin for primary CVD prevention in the US. ${ }^{15}$ The purpose of this study was to examine the association between an a priori defined set of demographic/clinical predictors and regular aspirin use in adults without CVD, diabetes, or USPSTFbased clinical indication ${ }^{14}$ for aspirin therapy for primary CVD prevention.

\section{Methods}

\section{Design and setting}

A cross-sectional analysis was performed using data from the Marshfield Clinic (headquarters Marshfield, WI, USA). The Marshfield Clinic is one of the largest private group medical practices in the US, with approximately 750 physicians serving over 300,000 patients annually across 45 clinics and 9 affiliated hospitals throughout central and northern Wisconsin. Patients' medical care and administrative information is documented in electronic health records (EHR). The target population for this study was the Marshfield
Epidemiologic Study Area (MESA). As described in more detail elsewhere, ${ }^{19}$ MESA is a regional population health research resource that tracks data from patients who seek their medical care at Marshfield Clinic and reside in 1 of 24 postal districts that surround Marshfield Clinic's primary service area, which is separated into two approximately equal-sized regions in central and northern Wisconsin. MESA has about 78,000 total residents, covers $7,500 \mathrm{~km}^{2}$, and is predominantly composed of small towns and rural/agricultural areas. Most residents in this area obtain their medical care from Marshfield Clinic providers and facilities. Previous research in this target population found that over $90 \%$ of outpatient and inpatient encounters are sought at Marshfield Clinic locations. ${ }^{20}$

\section{Sample}

All data were collected over 3 years, from January 1, 2010, to December 31, 2012. Eligibility criteria for this analysis were, as of December 31, 2012: 1) current living status in MESA, 2) $\geq 1$ ambulatory encounter with a Marshfield Clinic medical provider from January 1, 2010, to December $31,2012,3)$ age 30-79 years, 4) no personal history of ischemic vascular disease (eg, myocardial infarction, angina, ischemic stroke, peripheral artery disease) or diabetes (type 1 or type 2), and 5) not clinically indicated for aspirin therapy for primary CVD prevention, per the applicable USPSTF guidelines. ${ }^{14}$ The age bounds were based on the uncertainty of aspirin benefits in the elderly, as well as the very low likelihood of CVD and associated preventive medication use before age 30 . This was a retrospective analysis of previously collected healthcare data, and the study was approved by the Marshfield Clinic Institutional Review Board with a waiver of informed consent.

\section{Measures}

\section{Outcome}

The outcome of interest was regular use of aspirin-containing medication, as informed by previous EHR-based methods. ${ }^{21}$ Patient medication information (eg, initiation and discontinuation dates, frequency, dose) was collected during patient interviews conducted as part of routine clinic encounters. Medications were linked to the American Society of HealthSystem Pharmacists therapeutic classification system, ${ }^{22}$ and the generic names of five aspirin-containing, salicylate-class medications were extracted, including "aspirin", "aspirin/ calcium carb", "aspirin/magnesium carb/al aminoacet”, "aspirin/magnesium hydrox/al hydrox", and "aspirin/calcium carb/magnesium/al hydrox". Individuals who reported taking an aspirin-containing medication daily or every other day at 
their most recent encounter were considered current regular aspirin users. Those who took combined aspirin-narcotic or aspirin-caffeine agents, as well as those who took an aspirincontaining medication more than twice daily, were considered nonregular aspirin users in view of the transient nature of such therapies as a temporary analgesic. Also, individuals who did not take aspirin or otherwise took aspirin less frequently than every other day were considered nonregular aspirin users. Full aspirin dose information was reported descriptively where available, but not formally considered as part of the regular aspirin use definition owing to incomplete data.

\section{Aspirin indication}

The clinical indication for aspirin therapy was based on the current USPSTF guidelines for primary CVD prevention, ${ }^{14}$ which were released in 2009. Those indicated for aspirin included men aged 45-79 years with a moderate or greater 10 -year risk of coronary heart disease and women aged 55-79 years with a moderate or greater 10-year risk of stroke. The 10-year risk of coronary heart disease (for men) or stroke (for women) was calculated using the global CVD risk equation from the Framingham Heart Study. ${ }^{23}$ This method considers age, sex, smoking, systolic blood pressure, total cholesterol, and high-density lipoprotein (HDL) cholesterol in the risk score calculation. To provide some qualitative insights into the medical intent of aspirin use, chart reviews were performed on a randomly selected subset of 50 regular aspirin users. The explicitly documented reasons for aspirin use were reported descriptively.

\section{Predictors}

Considered predictor variables included the most recently known values for each individual Framingham risk factor, including age, sex, smoking, body mass index (BMI), systolic blood pressure, total cholesterol, and HDL cholesterol. In addition, race/ethnicity, health insurance status, MESA region (central or northern Wisconsin), and number of ambulatory medical encounters over the previous 3 years were also considered. All variables were collected by clinic staff following standard physical examination and laboratory procedures. BMI was calculated by dividing weight in kilograms by height in meters squared.

\section{Analyses}

Statistical analyses were conducted using $\mathrm{SAS}^{\circledR}$ (Version 9.3; SAS Institute Inc, Cary, NC, USA). Logistic regression was used to examine the association between predictor variables and regular aspirin use. Univariate associations between each predictor (separately) and aspirin were first examined. A multicollinearity check was performed on the variance inflation factor and condition index statistics for each predictor as well. ${ }^{24}$ Since no multicollinearity issues were observed, a fully adjusted model was created that considered all predictors simultaneously. A final reduced model was also fit by retaining only covariates with a significant $(P<0.05)$ association with regular aspirin use. Because Marshfield Clinic data on the MESA population represent a nearly complete capture of all medical care, no sample weighting techniques were used.

\section{Results}

Within the MESA population, there were 23,701 individuals aged 30-79 years without diabetes or CVD, and with complete data available to determine their clinical indication for aspirin therapy. Of these, 16,922 (71\%) were not clinically indicated for aspirin and were thus included in the analytical sample. As outlined in Table 1, the sample was predominantly female, reflecting the higher aspirin treatment threshold for women per the USPSTF criteria. Also, most individuals were non-Hispanic White and lived in central Wisconsin.

There were 3,159 (19\%) individuals who used aspirin regularly, with $97 \%$ indicating daily aspirin use. Full aspirin dose information was available on 549 aspirin users, with an average daily dose of $81 \mathrm{mg}$ being most common (75\%), followed by $325 \mathrm{mg}(22 \%), 162 \mathrm{mg}(2 \%)$, and >325 mg (1\%). Chart audits observed specific provider-documented recommendations for aspirin therapy in only $30 \%$ of regular aspirin users. These documented recommendations to take aspirin regularly were nearly always attributable to a preexisting nonischemic vascular comorbidity such as a congenital heart disorder or deep venous thrombosis, or were recommended without any explanation why. There were no observed provider-documented recommendations (nor patient-indicated reasons) to take aspirin regularly for pain control.

As outlined in Table 1, crude models indicated that all tested predictors were significantly associated with regular aspirin use. The full and reduced multivariable models are summarized in Table 2. In the reduced model, participants who were older, male, lived in northern Wisconsin, had more frequent medical visits, and had greater body mass had significantly higher odds of regular aspirin use $(P<0.001$ for all). Race/ethnicity, health insurance, smoking, blood pressure, and lipids had negligible influence on aspirin use. 
Table I Descriptive characteristics of adults not clinically indicated for aspirin therapy for primary cardiovascular disease prevention in 2012 , stratified by regular aspirin use

\begin{tabular}{|c|c|c|c|}
\hline Characteristics & $\begin{array}{l}\text { Regular } \\
\text { aspirin use } \\
(n=3,159)\end{array}$ & $\begin{array}{l}\text { Nonregular } \\
\text { aspirin use } \\
(n=13,763)\end{array}$ & $P$ \\
\hline Age (years) & & & $<0.001$ \\
\hline $30-39$ & $163(5)$ & $3,912(28)$ & \\
\hline $40-49$ & $390(12)$ & $4,27 \mid(3 I)$ & \\
\hline $50-59$ & $771(24)$ & $3,121(23)$ & \\
\hline $60-69$ & $\mathrm{I}, 06 \mathrm{I}(34)$ & $1,767(13)$ & \\
\hline $70-79$ & $774(25)$ & $692(5)$ & \\
\hline Sex & & & $<0.001$ \\
\hline Female & $2,738(87)$ & 10,677 (78) & \\
\hline Male & $42 I(13)$ & $3,086(22)$ & \\
\hline Race/ethnicity & & & $<0.001$ \\
\hline White, non-Hispanic & $3,040(96)$ & $12,912(94)$ & \\
\hline Non-White, non-Hispanic & $39(1)$ & $276(2)$ & \\
\hline Hispanic & $42(I)$ & $327(2)$ & \\
\hline Unknown & $38(I)$ & $248(2)$ & \\
\hline Health insurance & & & $<0.001$ \\
\hline Commercial only & $\mathrm{I}, 78 \mathrm{I}(56 \%)$ & $8,955(65 \%)$ & \\
\hline Public assisted & $1,322(42 \%)$ & $4,386(32 \%)$ & \\
\hline None & $56(2 \%)$ & $422(3 \%)$ & \\
\hline MESA region & & & $<0.001$ \\
\hline Central & $2,140(68)$ & $10,594(77)$ & \\
\hline North & $1,019(32)$ & $3,169(23)$ & \\
\hline Ambulatory visits in past 3 years & & & $<0.001$ \\
\hline $1-4$ & $488(15)$ & $3,779(27)$ & \\
\hline $5-8$ & $716(23)$ & $3,46 \mathrm{I}(25)$ & \\
\hline $9-14$ & $871(28)$ & $3,158(23)$ & \\
\hline$\geq 15$ & $\mathrm{I}, 084(34)$ & $3,365(24)$ & \\
\hline Smoking & & & $<0.001$ \\
\hline Current & $350(11)$ & $2,394(17)$ & \\
\hline Former or never & $2,809(89)$ & $11,369(83)$ & \\
\hline Body mass index & & & $<0.001$ \\
\hline Severely obese & $324(10)$ & $1,192(9)$ & \\
\hline Obese & $\mathrm{I}, 088(34)$ & $4,506(33)$ & \\
\hline Overweight & $1,044(33)$ & $4,384(32)$ & \\
\hline Healthy weight & $703(22)$ & $3,681(27)$ & \\
\hline Systolic blood pressure $(\mathrm{mmHg})$ & $126.2 \pm 16.5$ & $121.7 \pm 15.3$ & $<0.001$ \\
\hline Total cholesterol (mg/dL) & $194.0 \pm 34.7$ & $188.2 \pm 33.9$ & $<0.001$ \\
\hline HDL cholesterol (mg/dL) & $56.2 \pm 16.8$ & $52.8 \pm 16.3$ & $<0.001$ \\
\hline
\end{tabular}

Notes: Values are reported as mean \pm standard deviation or frequency (\% of total). $P$-value corresponds to the difference between aspirin use categories.

Abbreviations: MESA, Marshfield Epidemiologic Study Area; HDL, high-density lipoprotein.

Given the relatively large sample size, two follow-up sensitivity analyses were performed that tested 1) all possible two-way interaction terms (plus main effects) from the reduced model, and 2) a more conservative operational definition of nonregular aspirin users that excluded those individuals who used aspirin, but did so less frequently than daily or every other day. Full models are not shown from these sensitivity analyses, but as illustrated in Figure 1, there was one significant interaction observed between age and number
Table 2 Adjusted models of regular aspirin use among adults not clinically indicated for aspirin therapy for primary cardiovascular disease prevention $(n=16,922)$

\begin{tabular}{|c|c|c|}
\hline \multirow[t]{2}{*}{ Predictors } & \multicolumn{2}{|c|}{ Aspirin use $^{\mathrm{a}}$ (regular vs nonregular) } \\
\hline & $\begin{array}{l}\text { Fully adjusted } \\
\text { model }\end{array}$ & Reduced model \\
\hline \multicolumn{3}{|l|}{ Age (years) } \\
\hline \multirow{2}{*}{$40-49$ vs $30-39$} & $2.35(1.94,2.84)$ & $2.37(1.96,2.86)$ \\
\hline & $P<0.00$ I & $P<0.00$ I \\
\hline \multirow[t]{2}{*}{$50-59$ vs $30-39$} & $7.07(5.84,8.56)$ & $7.18(5.96,8.64)$ \\
\hline & $P<0.00$ I & $P<0.00$ I \\
\hline \multirow[t]{2}{*}{$60-69$ vs $30-39$} & I6.05 (I3.3I, 19.36) & $16.16(13.47,19.37)$ \\
\hline & $P<0.00$ I & $P<0.001$ \\
\hline \multirow[t]{2}{*}{$70-79$ vs $30-39$} & $29.79(24.18,36.68)$ & $29.21(23.98,35.58)$ \\
\hline & $P<0.001$ & $P<0.001$ \\
\hline \multicolumn{3}{|l|}{ Sex } \\
\hline \multirow[t]{2}{*}{ Female vs male } & $0.66(0.57,0.75)$ & $0.65(0.57,0.74)$ \\
\hline & $P<0.001$ & $P<0.001$ \\
\hline \multicolumn{3}{|l|}{ Race/ethnicity } \\
\hline \multicolumn{3}{|l|}{ Non-White, } \\
\hline non-Hispanic vs & $P=0.999$ & \\
\hline \multicolumn{3}{|l|}{ White, non-Hispanic } \\
\hline Hispanic vs White, & \multicolumn{2}{|l|}{$1.04(0.72, \mathrm{I} .48)$} \\
\hline non-Hispanic & \multicolumn{2}{|l|}{$P=0.853$} \\
\hline Unknown vs White, & \multicolumn{2}{|l|}{$1.08(0.74,1.56)$} \\
\hline non-Hispanic & \multicolumn{2}{|l|}{$P=0.658$} \\
\hline \multicolumn{3}{|l|}{ Health insurance } \\
\hline Public assisted vs & $0.94(0.83,1.01)$ & - \\
\hline commercial & \multicolumn{2}{|l|}{$P=0.086$} \\
\hline \multirow[t]{2}{*}{ None vs commercial } & \multicolumn{2}{|l|}{$0.92(0.69,1.27)$} \\
\hline & \multicolumn{2}{|l|}{$P=0.688$} \\
\hline MESA region & & \\
\hline Central vs north & $0.72(0.66,0.80)$ & $0.73(0.67,0.80)$ \\
\hline & $P<0.001$ & $P<0.001$ \\
\hline Ambulatory visits in past 3 & ears & \\
\hline $5-8$ vs $I-4$ & $1.36(1.19,1.55)$ & $1.35(1.18,1.54)$ \\
\hline & $P<0.00 I$ & $P<0.00 \mathrm{I}$ \\
\hline $9-14$ vs I-4 & $1.69(1.48,1.93)$ & $1.68(1.47,1.91)$ \\
\hline & $P<0.001$ & $P<0.001$ \\
\hline$\geq 15$ vs $1-4$ & $2.1 \mathrm{I}(\mathrm{I} .85,2.4 \mathrm{I})$ & $2.08(1.83,2.36)$ \\
\hline & $P<0.00$ I & $P<0.00$ I \\
\hline Smoking & & \\
\hline Current vs former & $1.00(0.87,1.14)$ & - \\
\hline or never & $P=0.964$ & \\
\hline Body mass index & & \\
\hline Overweight vs healthy & $1.19(1.05,1.34)$ & $1.21(1.08,1.36)$ \\
\hline weight & $P=0.005$ & $P=0.001$ \\
\hline Obese vs healthy & $1.26(1.11,1.42)$ & $1.30(1.16,1.46)$ \\
\hline weight & $P<0.001$ & $P<0.001$ \\
\hline Severely obese vs & $1.57(1.33,1.87)$ & $1.64(1.39,1.93)$ \\
\hline healthy weight & $P<0.001$ & $P<0.001$ \\
\hline Systolic blood pressure & $1.00(1.00,1.01)$ & - \\
\hline$(\mathrm{mmHg})$ & $P=0.076$ & \\
\hline Total cholesterol (mg/dL) & $1.00(1.00,1.00)$ & - \\
\hline & $P=0.915$ & \\
\hline HDL cholesterol (mg/dL) & $1.00(0.99,1.00)$ & - \\
\hline & $P=0.320$ & \\
\hline
\end{tabular}

Notes: a ${ }^{2}$ alues are reported as odds ratio ( $95 \%$ confidence interval) of regular aspirin use. Values greater than 1.00 indicate that, relative to the reference category (or a I-unit increase for continuous predictors), the odds of regular aspirin use increased. - indicates variables not included in the reduced model.

Abbreviations: MESA, Marshfield Epidemiologic Study Area; HDL, high-density lipoprotein; vs, versus. 


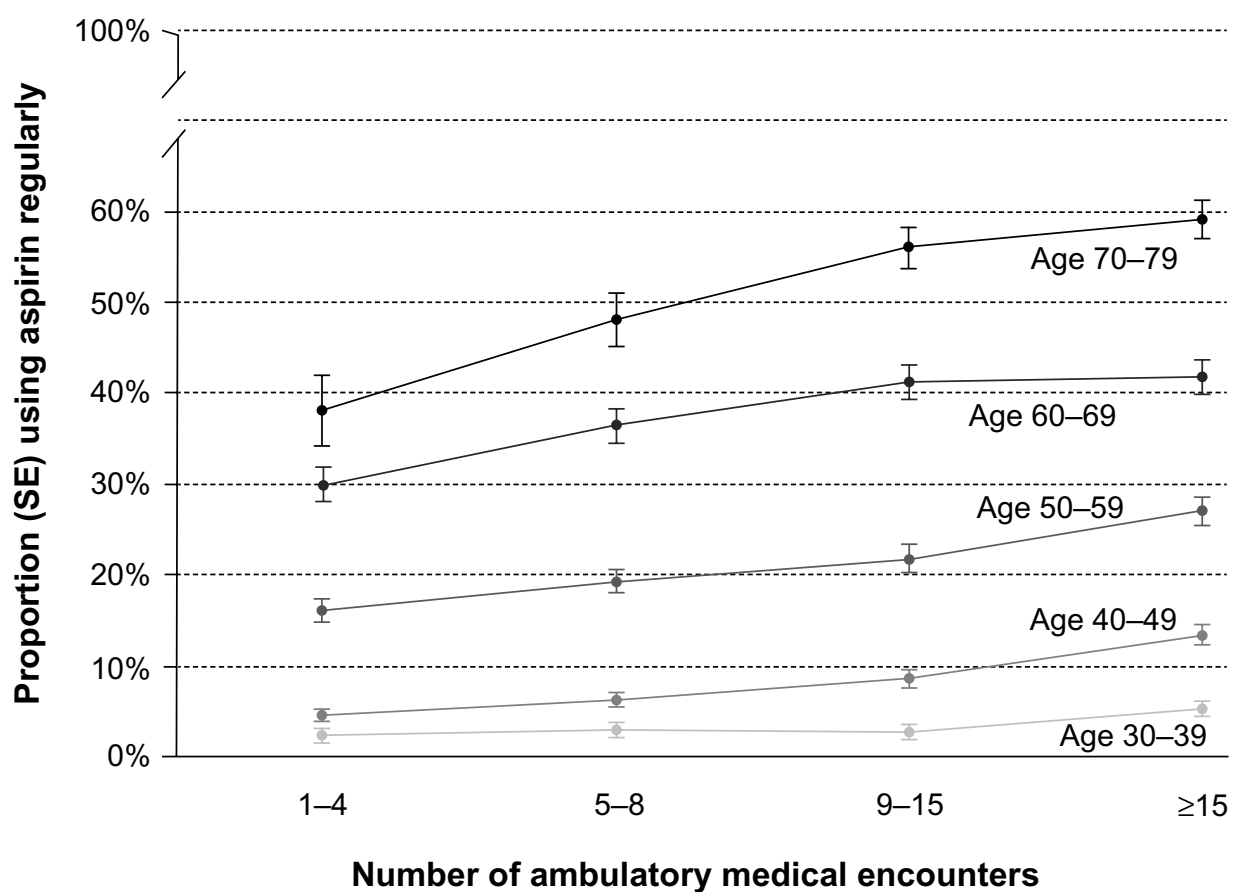

Figure I Proportion of regular aspirin users among adults not clinically indicated for aspirin therapy for primary cardiovascular disease prevention. Notes: Based on a sensitivity analysis model stratified by age and number of ambulatory medical care encounters over the previous 3 years. Abbreviation: SE, standard error.

of ambulatory care encounters (interaction, $P=0.017$; main effect for age, $P<0.001$; main effect for number of encounters, $P=0.002$ ), indicating a progressively greater proportion of regular aspirin users among older age groups who visited their provider more frequently. The second sensitivity analysis resulted in the exclusion of 64 individuals from the nonregular aspirin use group, with associations nearly identical to those observed in the main analysis.

Identical analyses were also run for both males and females separately. The significant predictors and directions of their association were identical for both men and women, thus sex-stratified analyses were not reported.

\section{Discussion}

As previously observed in Europe, ${ }^{12,16}$ there was clearly aspirin overutilization in this sample of MESA adults, with about one in every five regularly using aspirin despite no USPSTF-based clinical indication for doing so for primary CVD prevention. This is consistent with other recent findings from Wisconsin. ${ }^{18}$ Also consistent with previous findings from the region, ${ }^{21}$ males were more likely to use aspirin, and older individuals who visited their medical provider often had a particularly strong likelihood of regular aspirin use. Obesity was the only clinical CVD risk factor associated with inappropriate aspirin use in this otherwise low-CVD-risk population. Other tested clinical and demographic factors had little influence on aspirin use in adjusted models.

It was somewhat surprising that higher BMI tracked with inappropriate aspirin use, with overweight, obese, and severely obese adults being incrementally more likely to regularly use aspirin as compared to healthy weight adults. Reasons for this are speculative given the limited chart documentation on aspirin use, but may reflect strong obesity risk perceptions that influence patient decisions. Adults without CVD consider obesity a top health risk factor of concern, ${ }^{25}$ and this motivates related medical decisions such as bariatric surgery. ${ }^{26}$ Perhaps the higher likelihood of inappropriate aspirin use in heavier adults is a manifestation of the widely recognized obesity risks and aspirin being a familiar, routinely marketed over-the-counter CVD remedy. ${ }^{8,12}$ There are also concerns regarding primary medical care for obese patients, with weight-related risks sometimes dominating the clinical encounter at the detriment of other preventive health screenings. ${ }^{27,28}$ Physician advice to take aspirin is more likely to be guided by subjective appraisals of cardiovascular health ${ }^{29}$ rather than formal, objectively calculated CVD risk scores. ${ }^{30}$ Although obesity is an independent CVD risk factor, it may go underappreciated that, in the presence of other proximal risk factors (eg, high blood pressure, hyperlipidemia, smoking), obesity adds limited incremental value to predicting incident CVD. ${ }^{31,32,33}$ The USPSTF aspirin guidelines are 
based on the near-term 10-year risk of CVD, where body weight is not usually considered. But a myocardial infarction is obviously a debilitating event that seems to foster severer trepidations than a bleeding event. ${ }^{34,35}$ As such, aspirin may essentially be considered "worth the risk" for many obese patients because bleeds can be controlled to some degree. ${ }^{36}$ Given that higher body mass mitigates some platelet inhibition properties of aspirin, ${ }^{37}$ thereby diminishing the prospects of cardioprotection in obese adults, clinical guidelines in this area could use further refinement by examining incident CVD and major bleeding events related to regular aspirin use among adults at various levels of BMI. Future studies might also benefit from more detailed insights into patient and provider perceptions regarding aspirin benefits.

The combined observations that aspirin is generally overutilized in low-CVD-risk groups and underutilized in high-CVD-risk groups, ${ }^{18,21}$ as well as consistent indications that physician advice to use aspirin is highly motivating for patients, ${ }^{8,38,39}$ highlight the need for better clinical tools to optimize aspirin utilization in primary prevention settings. The typical primary care environment, however, lacks convenient means to identify a given patient's synchronization with the USPSTF aspirin guidelines. Development and utilization of clinical decision support aids that capitalize on EHR technologies to quickly and precisely screen patients for aspirin indication (including aspirin contraindications) would seem useful, ${ }^{40,41}$ particularly if combined with care follow-up ${ }^{42}$ and quality improvement monitoring. ${ }^{43,44}$

Potential measurement and misclassification biases were the main study limitations. This was a retrospective analysis of data collected from patient interviews during routine clinical encounters documented in the EHR; thus some metrics may have been less reliable or underreported relative to what might be observed in more controlled, prospective research settings. Precise aspirin dosage information was often unavailable. Validation studies of self-reported aspirin use indicate good accuracy and correlation with biomarkers in other populations, ${ }^{45}$ but were not performed here. The timing of the aspirin assessment at the most recent visit could also be problematic if it mistakenly identifies some patients who are temporarily using aspirin regularly. Also, the specific patientreported and/or provider-directed reasons for aspirin use were rarely documented in medical charts. It had to be assumed that the primary intent of regular aspirin use for cases in this study was for CVD prevention, which may be reasonable, given that CVD prevention is by far the most common reason cited by regular aspirin users in other contemporary studies. ${ }^{39,46}$ However, this is important to confirm in medical records data, and future research should consider complementary patient interviews to validate the reason for aspirin use, as well as a greater number of chart audits conducted by experienced primary care physicians that can identify other possible, indirectly documented reasons for aspirin use (eg, extensive family history of CVD, chronic pain issues, temporary use due to specific medical procedures). Other study limitations involved the racial/ethnic homogeneity of the target population that restricts generalizability. The sensitivity analyses that examined interactions were performed post hoc for hypothesis generation purposes; thus, they may have been underpowered to examine some subgroups. Related to that, the number of ambulatory care encounters was modeled categorically because of its skewed distribution. Future research should consider a more detailed investigation of the impact of clinic visits on inappropriate aspirin use, including provider types and possible threshold effects for the number of visits.

This study found that older males who visit their provider frequently were most likely to inappropriately use aspirin for primary CVD prevention. Excess body weight was also a persistent clinical factor explaining inappropriate aspirin use. As in much of the US, obesity is widespread in the MESA population, and more research is needed to better understand the potential interplay between obesity, regular aspirin use, and the risks of both CVD and major bleeding. Collective findings from this study, if replicated in broader samples and the reasons for aspirin use verified, may signal an overemphasis of CVD risk and/or aspirin benefits by some patient groups and their medical providers. Given some of the uncertainties of aspirin used in the context of primary CVD prevention in the US, ${ }^{15}$ fuller development and use of office-based technologies that can quickly screen for patients who should or should not be using aspirin for primary CVD prevention, based on established clinical guidelines, ${ }^{14}$ are encouraged.

\section{Acknowledgments}

This research was supported by the Marshfield Clinic Celine Seubert Distinguished Physician Endowment in Cardiology Research, as well as the Clinical and Translational Science Award (CTSA) program, through the US National Institutes of Health (NIH) National Center for Advancing Translational Sciences (NCATS), grant UL1TR000427. The content is solely the responsibility of the authors and does not necessarily represent the official views of the NIH.

\section{Disclosure}

The authors report no conflicts of interest in this work. 


\section{References}

1. Hsu S, Ton VK, Dominique Ashen M, et al. A clinician's guide to the $\mathrm{ABC}$ of cardiovascular disease prevention: the Johns Hopkins Ciccarone Center for the Prevention of Heart Disease and American College of Cardiology Cardiosource approach to the Million Hearts Initiative. Clin Cardiol. 2013;36:383-393.

2. Hennekens $\mathrm{CH}$, Schneider WR. The need for wider and appropriate utilization of aspirin and statins in the treatment and prevention of cardiovascular disease. Expert Rev Cardiovasc Ther. 2008;6:95-107.

3. US Preventive Services Task Force. Aspirin for the primary prevention of cardiovascular events: Recommendation and rationale. Ann Intern Med. 2002;136:157-160.

4. Maciosek MV, Coffield AB, Edwards NM, et al. Priorities among effective clinical preventive services: results of a systematic review and analysis. Am J Prev Med. 2006;31:52-61.

5. Bartolucci AA, Tendera M, Howard G. Meta-analysis of multiple primary prevention trials of cardiovascular events using aspirin. Am J Cardiol. 2011;107:1796-1801.

6. Ajani UA, Ford ES, Greenland KJ, Giles WH, Mokdad AH. Aspirin use among US adults: behavioral risk factor surveillance system. Am J Prev Med. 2006;30:74-77.

7. Sanchez DR, Diez Roux AV, Michos ED, et al. Comparison of the racial/ ethnic prevalence of regular aspirin use for the primary prevention of coronary heart disease from the multi-ethnic study of atherosclerosis. Am J Cardiol. 2011;107:41-46.

8. Pignone M, Anderson GK, Binns K, Tilson HH, Weisman SM. Aspirin use among adults aged 40 and older in the United States: results of a national survey. Am J Prev Med. 2007;32:403-407.

9. Barnett H, Burrill P, Iheanacho I. Don't use aspirin for primary prevention of cardiovascular disease. BMJ. 2010;340:c1805.

10. Sanchez-Ross M, Waller AH, Maher J, et al. Aspirin for the prevention of cardiovascular morbidity. Minerva Med. 2010;101:205-214.

11. Filippi A, Bianchi C, Parazzini F, et al. A national survey on aspirin patterns of use and persistence in community outpatients in Italy. Eur J Cardiovasc Prev Rehabil. 2011;18:695-703.

12. Rodondi N, Cornuz J, Marques-Vidal P, et al. Aspirin use for the primary prevention of coronary heart disease: a population-based study in Switzerland. Prev Med. 2008;46:137-144.

13. De Berardis G, Lucisano G, D'Ettorre A, et al. Association of aspirin use with major bleeding in patients with and without diabetes. JAMA. 2012;307:2286-2294.

14. US Preventive Services Task Force. Aspirin for the prevention of cardiovascular disease: US preventive services task force recommendation statement. Ann Intern Med. 2009;150:396-404.

15. US Food and Drug Administration. Use of Aspirin for Primary Prevention of Heart Attack and Stroke [updated June 13, 2014]. Available from: http://www.fda.gov/drugs/resourcesforyou/consumers/ ucm390574.htm. Accessed June 27, 2014.

16. Manes C, Giacci L, Sciartilli A, D’Alleva A, De Caterina R. Aspirin overprescription in primary cardiovascular prevention. Thromb Res. 2006;118:471-477.

17. Kale MS, Bishop TF, Federman AD, Keyhani S. Trends in the overuse of ambulatory health care services in the United States. JAMA Intern Med. 2013;173:142-148.

18. VanWormer JJ, Greenlee RT, McBride PE, et al. Aspirin for primary prevention of CVD: are the right people using it? J Fam Pract. 2012;61: $525-532$.

19. DeStefano F, Eaker ED, Broste SK, et al. Epidemiologic research in an integrated regional medical care system: the Marshfield Epidemiologic Study Area. J Clin Epidemiol. 1996;4:643-652.

20. Greenlee RT. Measuring disease frequency in the Marshfield Epidemiologic Study Area (MESA). Clin Med Res. 2003;1: 273-280.

21. VanWormer JJ, Miller AW, Rezkalla SH. Identifying opportunities to improve aspirin utilization for the primary prevention of cardiovascular disease in a regional healthcare system. WMJ. 2014;113(5): $190-195$.
22. American Society of Health-System Pharmacists. AHFS Drug Information 2013. Bethesda, MD: American Society of Health-System Pharmacists; 2013.

23. D'Agostino RB Sr, Vasan RS, Pencina MJ, et al. General cardiovascular risk profile for use in primary care: the Framingham Heart Study. Circulation. 2008;117:743-753.

24. Cody RP, Smith JK. Applied Statistics and the SAS Programming Language. New York, NY: Prentice Hall; 2005.

25. Kastorini CM, Georgousopoulou E, Vemmos KN, et al. Comparative analysis of cardiovascular disease risk factors influencing nonfatal acute coronary syndrome and ischemic stroke. Am J Cardiol. 2013;112: 349-354.

26. Prasad C, Batsis JA, Lopez-Jimenez F, Clark MM, et al. Risk perception of obesity and bariatric surgery in patients seeking treatment for obesity. Eur J Prev Cardiol. 2012;21:692-703.

27. Hernandez-Boussard T, Ahmed SM, Morton JM. Obesity disparities in preventive care: findings from the National Ambulatory Medical Care Survey, 2005-2007. Obesity. 2012;20:1639-1644.

28. Bertakis KD, Azari R. The impact of obesity on primary care visits. Obes Res. 2005;13:1615-1623.

29. Mosca L, Linfante AH, Benjamin EJ, et al. National study of physician awareness and adherence to cardiovascular disease prevention guidelines. Circulation. 2005;111:499-510.

30. Shillinglaw B, Viera AJ, Edwards T, Simpson R, Sheridan SL. Use of global coronary heart disease risk assessment in practice: a cross-sectional survey of a sample of US physicians. BMC Health Serv Res. 2012;12:20.

31. Ridker PM, Buring JE, Rifai N, Cook NR. Development and validation of improved algorithms for the assessment of global cardiovascular risk in women: the Reynolds Risk Score. JAMA. 2007;297:611-619.

32. Pencina MJ, D’Agostino RB Sr, Larson MG, Massaro JM, Vasan RS. Predicting the 30-year risk of cardiovascular disease: the framingham heart study. Circulation. 2009;119:3078-3084.

33. Freiberg MS, Pencina MJ, D’Agostino RB, et al. BMI vs waist circumference for identifying vascular risk. Obesity. 2008;16:463-469.

34. Hennekens CH, Dalen JE. Aspirin in the treatment and prevention of cardiovascular disease: past and current perspectives and future directions. Am J Med. 2013;126:373-378.

35. Morgan G, Elwood P. Aspirin bleeding in perspective. Qual Prim Care. 2011;19:251-253.

36. Adly G, Plakogiannis R. Reinitiating aspirin therapy for primary prevention of cardiovascular events in a patient post-aspirin-induced upper gastrointestinal bleed: a case report and review of literature. Ann Pharmacother. 2013;47:e8.

37. Santilli F, Vazzana N, Liani R, Guagnano MT, Davì G. Platelet activation in obesity and metabolic syndrome. Obes Rev. 2012;13:27-42.

38. O'Connor PJ, Pronk NP, Tan AW, Rush WA, Gray RJ. Does professional advice influence aspirin use to prevent heart disease in an HMO population? Eff Clin Pract. 1998;1:26-32.

39. Kolber M, Sharif N, Marceau R, Szafran O. Family practice patients' use of acetylsalicylic acid for cardiovascular disease prevention. Can Fam Physician. 2013;59:55-61.

40. Sheridan SL, Draeger LB, Pignone MP, et al. A randomized trial of an intervention to improve use and adherence to effective coronary heart disease prevention strategies. BMC Health Serv Res. 2011;11:331.

41. Appana D, Sperl-Hillen J, Ekstrom H, et al. Aspirin decision support using data-driven treatment algorithms. Clin Med Res. 2013;11: $136-137$.

42. Benson GA, Sidebottom A, VanWormer JJ, et al. HeartBeat Connections: a rural community of solution for cardiovascular health. J Am Board Fam Med. 2013;26:299-310.

43. Folks B, Leblanc WG, Staton EW, Pace WD. Reconsidering low-dose aspirin therapy for cardiovascular disease: a study protocol for physician and patient behavioral change. Implement Sci. 2011;6:65.

44. Wisconsin Collaborative for Healthcare Quality. Ischemic Vascular Disease: Daily Aspirin or Other Antiplatelet Therapy. Available from: http://www.wchq.org/reporting/results.php?category_id=0\&topic_ id=27\&source_id=0\&providerType $=0$ \&region $=0 \&$ measure_id= 156 . Accessed July 7, 2014. 
45. Zantek ND, Luepker RV, Duval S, et al. Confirmation of reported aspirin use in community studies: utility of serum thromboxane B2 measurement. Clin Appl Thromb Hemost. 2014;20: $385-392$.
46. Pakhomov SV, Shah ND, Hanson P, Balasubramaniam SC, Smith SA. Automated processing of electronic medical records is a reliable method of determining aspirin use in populations at risk for cardiovascular events. Inform Prim Care. 2010;18:125-133.

\section{Publish your work in this journal}

Clinical Epidemiology is an international, peer-reviewed, open access, online journal focusing on disease and drug epidemiology, identification of risk factors and screening procedures to develop optimal preventative initiatives and programs. Specific topics include: diagnosis, prognosis, treatment, screening, prevention, risk factor modification,

Submit your manuscript here: http://www.dovepress.com/clinical-epidemiology-journal

\section{Dovepress}

systematic reviews, risk \& safety of medical interventions, epidemiology \& biostatistical methods, and evaluation of guidelines, translational medicine, health policies \& economic evaluations. The manuscript management system is completely online and includes a very quick and fair peer-review system, which is all easy to use. 